\title{
TOPOGRAFÍA DE LA AMAZONÍA PERUANA en "Sangama" de Arturo HERNÁNDEZ
}

\section{Ulises Juan Zevallos Aguilar}

$\mathbb{E}_{n}$ este artículo se examina la contradictoria concepción que tiene la población ribereña sobre la selva en la novela "Sangama" de Arturo Hernández. También se analiza el proyecto de modernización que se desprende de esta concepción. Se señala que este proyecto no es factible debido a que está basado en una visión que en vez de su desarrollo promoverá mas bien su destrucción.

In this article, the author examines how the riverine population conceives the jungle in the novel "Sangama" by Arturo Hernández. The modernization project related to this contradictory conception is also studied. The author arrives at the conclusion that this project is not feasible due in part to the fact that it is based on a vision that will provke its destruction instead of promoting its development. 
La lectura del canon de la literatura regional latinoamericana generó la escritura de una oleada de obras literarias regionalistas en el Perú en las cinco primeras décadas del siglo XX. El éxito alcanzado por "Don Segundo Sombra", "La Vorágine" y "Doña Bárbara" y la predicación de los escritores regionalistas impulsaron a escritores peruanos a que se dedicaran a retratar en sus novelas la inmensa diversidad de espacios regionales que constituyen la realidad peruana. En el presente se desconoce u olvida la existencia de estas obras literarias. Todavía se mantiene un prejuicio generalizado sobre ellas que fue modelado por la feroz campaña de desprestigio que algunos escritores del "boom" literario latinoamericano (Carlos Fuentes y Mario Vargas Llosa) emprendieron contra el canon de la literatura regional. ${ }^{1}$ En los últimos años, la crítica literaria latinoamericana se ha encargado de aclarar los motivos de esta campaña y, por cierto, de rescatar el valor literario de los textos canónicos (Alonso 1990:44). Queda todavía pendiente la tarea de emprender una relectura de los textos que alcanzaron consagración en el ámbito nacional y la de iniciar una lectura de la inmensa cantidad de textos que no fueron leídos por los críticos para tener una idea más completa y cabal de la narrativa regional latinoamericana.

Existe un considerable número de novelas peruanas con tema amazónico. Arturo D. Hernández (1903-1970) dedicó una trilogía de novelas a la Amazonía: "Sangama" (1942), "Selva trágica" (1954) y "Bubinzana" (1960). En esta oportunidad voy a explorar la novela "Sangama" subtitulada Novela de la selva amazónica. Esta novela es el texto literario más representativo de la narrativa amazónica peruana. Desde su aparición el pacto de lectura y las concepciones realistas de la novela consideraron a "Sangama" una representación fiel de la selva. Por esta razón la novela ha sido editada varias veces. La primera edición fue publicada por el Comité del IV Centenario del Descubrimiento del Río Amazonas, bajo los auspicios del Presidente de la República, doctor Manuel Prado. Por los auspicios del gobierno peruano y el momento celebratorio en el que se publicó, "Sangama" alcan-

Recuérdese que Mario Vargas Llosa llamó "novela primitiva” a la novela regional. 
zó prestigio internacional cuando fue traducida a varias lenguas europeas diez años después de la edición en castellano. El éxito alcanzado por la novela, principalmente en lengua francesa, generó una secuela de obras que exploraron la región selvática por escritores que no han alcanzado el prestigio de Hernández.

El estudio de "Sangama" se hace indispensable porque ha contribuido a la formación de una visión de la Amazonía en varias generaciones de lectores peruanos. "Sangama" es una de las novelas más leídas por el público lector peruano. A partir de la década del cincuenta, ha sido editada legalmente en ediciones masivas por lo menos unas 10 veces hasta los años noventa. Más aún, la influencia de "Sangama" ha sido reforzada en sus lectores debido a que cuenta con una versión en historieta. Hay demasiadas coincidencias para poder afirmar que las características y aventuras del héroe de historieta "Loreto" tienen como modelo a "Sangama". Esta historieta apareció por primera en la revista de circulación masiva "Avanzada" (19541968) y fue reimpresa en el diario "Expreso" por lo menos dos veces. ${ }^{2} \mathrm{Si}$ bien la novela no ha recibido mucha atención de la crítica académica actual, ésta despierta el interés en lectores jóvenes de distintas generaciones que quedan deslumbrados por las aventuras del héroe Sangama y se identifican con el proceso de maduración personal de Abel Barcas, narrador personaje que retorna a la selva "pleno de esperanzas y sediento de aventuras". En efecto, la novela es un bildunsgroman atractivo para lectores jóvenes que agotan las sucesivas ediciones que salen al mercado o compran la novela en el mercado informal de libros usados. ${ }^{3}$ La vida de Abel Barcas es un modelo a seguir puesto que, aparte de tener muchas aventuras de vida o muerte, se debate entre el amor y el deseo cuando se enamora de su futura esposa y satisface sus ambiciones económicas cuando consigue un prometedor trabajo en la selva.

Una indagación más detallada sobre "Loreto" puede encontrarse en mí artículo "La experiencia de Avanzada. Misiones, medios masivos e identidad amazónica".

"Sangama" es una novela infaltable en el stock de vendedores callejeros de libros que venden libros usados o ediciones piratas. 
Mario Vargas Llosa calificaba de primitiva a la novela regional porque "la novela se convirtió en un censo, materia de datos geográficos, una descripción de usos y costumbres, un documento etnológico, una feria regional, un muestrario de folklore" (citado por Alonso 1990: 38). En este trabajo, las dimensiones de la novela regional que Vargas Llosa desprecia pasan a ser materia de estudio. Sobretodo me interesa explorar el examen topográfico de la Amazonía que se lleva a cabo en "Sangama" sin mayores pretensiones literarias. ${ }^{4}$ Es decir, en la novela se emprende una descripción pormenorizada del territorio, flora y fauna de la región del bajo Ucayali y se utilizan los dispositivos de la novela de aventuras para hacer amena la lectura de la topografía. 5 Del mismo modo, en "Sangama" se asume que este examen topográfico es un conocimiento técnico, objetivo, racional e ilustrado. También se reclama implícitamente que tal conocimiento es universal en su alcance y libre de intereses políticos y culturales. Pero no hay que olvidar que la

“...topografia también es una práctica, es un conocimiento puesto en práctica y al servicio del poder. Por lo tanto está profundamente entretejido en las redes culturales, sociales y politicas de la sociedad. Tal conocimiento es propuesto para describir la forma en la cual una formación social es hecha visible en la faz de la tierra. Es una práctica que describe fronteras, incluyendo relaciones de propiedad, y por lo tanto las hace concretas, las racionaliza y las hace parecer como objetos naturales a través de la retórica del discurso cientifico. Por lo tanto la topografia es también una

Al respecto Hernández opina: "Yo también he escrito siempre ignorando la existencia de la técnica; simplemente escribo sobre mis experiencias y mis impresiones en la selva virgen de donde soy natural, de Loreto. Mis personajes siempre están conectados con el medio fisico, tal vez el medio fisico sea el protagonista de mis obras. Me identifico especialmente con el protagonista de la obra" (1942: 174).

5 Hernández introduce al lector a este espacio con la siguiente descripción: "Esta región, una de las más extrañas de la Tierra, está cubierta de selva impenetrable. En su interior no ha podido habitar en forma permanente el hombre. El ancho curso de agua que al cruzarla toma el nombre de Bajo Ucayali, adquiere una peculiaridad salvaje. Es un monstruo caprichoso que, según las estaciones, es río unas veces, $y$ otras. 
ciencia de dominación al confirmar fronteras, asegurar normas y al tratar convenciones sociales cuestionables como si fueran hechos sociales incuestionables..." (Duncan y Ley 1993:1).

El carácter topográfico de "Sangama" no debería sorprender al lector. El origen de esta novela fue una monografía que Arturo Hernández presentó en la Universidad de San Marcos para aprobar el curso de Geografía Humana. Esta monografía le sirvió a Hernández no sólo para alcanzar prestigio social y académico sino para ser considerado el portavoz de la selva cuando fue nombrado miembro activo de la Sociedad Geográfica de Lima. Esta institución le encargó a Hernández escribir un artículo sobre la selva. Hernández no publicó tal artículo. Este se convirtió en "Sangama" después de tres años de escritura. ${ }^{6}$ Cuando se lee la novela pareciera que Hernández dividió la monografía en segmentos y los insertó en un relato ficticio de las aventuras del narrador personaje Abel Barcas, quien establece una entrañable amistad con Sangama el héroe de la novela. La amistad se inicia después de que Sangama salva la vida a Abel Barcas. Luego se refuerza cuando Sangama se convierte en un maestro que le enseña los secretos más profundos de la selva virgen a Abel Barcas cuando ambos llevan a cabo una expedición para encontrar shiringales (tierras caucheras).

Si bien el estilo de la monografía fue elogiado por los estudiantes y el maestro de geografía, los críticos literarios consideraron a la novela como un texto simple, sin mayor uso de técnicas literarias. ${ }^{7}$ En efecto, en el texto no se despliega un mayor virtuosismo literario. El mismo Hernández se encargó de remarcar este aspecto en reiteradas oportunidades. En breve, "Sangama" es una novela lineal de 475 páginas monocorde que no recons-

\footnotetext{
Ver sus declaraciones en "Primer encuentro de narradores peruanos", p. 47.

Luis Alberto Sánchez señala que la novela tiene un gran sencillez y se deja arrastrar por los hechos. Si bien esta sencillez provocó el olvido y menosprecio de la crítica académica, esta característica logró el acercamiento con sus lectores populares. Por su parte, Washington Delgado comenta sobre Hernández. "Su major mérito reside en la descripción realista de personajes y paisajes de la selva; pero se ve empañado por la truculencia de sus temas. Es un narrador fácil, algo folletinesco y de espontáneo realismo".
} 
truye, por ejemplo, los registros de la oralidad amázonica. Todos los personajes, foráneos y propios del lugar, hablan en un castellano estandard saturado de una retórica emotiva. Asimismo, las referencias al canon de la literatura regional son demasiado evidentes.

Es un hecho que los modelos para escribir "Sangama” fueron "Doña Bárbara", "La Vorágine" y "Don Segundo Sombra". Sin embargo, en "Sangama" se supera la contradicción existente entre el "retorno a lo natural y al tiempo" y las propuestas de modernización que la novela regional plantea (Marcone 1998:300). La razón que permite superar este impase es que en la topografía de la novela se registran varios conocimientos locales de la Amazonía peruana y desde estos conocimientos se plantea una modernización alternativa de la selva peruana.

En la novela los personajes poseen varios niveles de conocimiento local de los espacios que componen el complejo ecosistema amazónico. De este modo, desde una marcada conciencia regional y con precisión topográfica se señala explícitamente que se va a representar la región del Bajo Ucayali y no el río Ucayali o la Amazonía en general. Hernández sabía que la mayor parte del curso del Ucayali corre en una planicie cambiante de aluviones recientes y una pequeña parte más alta (Alto Ucayali) formada por sedimentos más antiguos. La diferencia de alturas hace que existan dos tipos de orillas que corresponden a un asentamiento estacional para "cultivos migratorios" y a otro permanente "asentamientos humanos" (Tournon 1988: 48-49). Está precisión topográfica, también llevó a que Arturo Hernández no perpetuara el mito de la homogeneidad que "considera a la región como un 'inmenso infierno verde', cubierto de bosques y de aguas, sin mayores variaciones y donde se pueden aplicar sistemas de desarrollo homogéneos" (Brack Egg 1992:10). De la misma manera el conocimiento

\footnotetext{
Abel Barcas tiene características de Santos Luzardo. El modelo de representación de la selva es de "La Vorágine". El proceso de aprendizaje de Abel Barcas se parece mucho al de Fabio Cáceres de "Don Segundo Sombra". Asimismo, el tópico del retorno al lugar de origen de la novela regional aparece en "Sangama".
} 
local hace que no se prolongue el mito del vacío amazónico. En la novela se alude a la existencia de indígenas en general y se registra la multietnicidad de esta población indígena cuando son descritas las costumbres de Chamas, Jíbaros, etc. Según Abel Barcas "Esta región, una de las más extrañas de la Tierra, está cubierta de selva impenetrable. En su interior no ha podido habitar en forma permanente el hombre" (94). Por otro lado, no obstante la conciencia de que se está abordando una región específica, en la novela se la fragmenta aún más, en partes más pequeñas, para describirla. Así podemos apreciar como, Abel Barcas transmite su conocimiento de los microclimas de las riberas amazónicas. Sangama transmite el conocimiento de la selva virgen a Abel Barcas (165). Hay algunas referencias a conocimientos subordinados indígenas que no se profundizan (64). ${ }^{9}$ Por último, se describen los conocimientos de científicos europeos que ya están explorando la Amazonía. ${ }^{10}$

Definitivamente, en la minuciosa topografía de la selva de "Sangama" se privilegia el conocimiento local de la población ribereña como factor legitimante de su proyecto político para la región. Los conocimientos de los otros habitantes de la Amazonía se incluyen en este proyecto pero se excluyen a los sujetos de conocimiento. En este sentido, Abel Barcas como protagonista de la novela compila todos estos conocimientos para aplicarlos a la explotación de caucho de esta región en beneficio propio. De allí que Abel Barcas, relate su retorno en los siguientes términos:

“...Hacen [sic] veintidós años que yo nací por acá y, nadie podría decirme con exactitud, dónde. Mi padre fué [sic] uno de los primeros caucheros que exploraron estas selvas. Ahora ha empobrecido en Barbados y yo vengo con la intención de rehacer la fortuna, arrancando, como él supo hacerlo, tesoros a la selva..."(6).

9 No hay una profundización de la concepción del espacio indígena como la explora Fernando Santos Granero en su artículo "Writing History into the Landscape: space, myth and ritual".

10 Este artículo es complementario con el trabajo de Ileana Rodríguez en este volumen que rastrea los conocimientos de sujetos de conocimiento europeos de la amazonía desde el siglo XVI hasta el presente. 
La descripción de la región del Bajo Ucayali, a diferencia de la novela regional canónica que sataniza la selva a partir de la relación conflictiva que establece entre hombre y naturaleza, revela que aun los lugares más peligrosos e inexpugnables pueden ser superados con un conocimiento adecuado. En términos más simples, Sangama, que no es originario de la selva, después de varios años de observarla llega a conocerla profundamente para sobrevivir en ella(199). De otra parte, la minuciosidad de la topografía, junto a una definitiva visión positiva del espacio amazónico, revela un amor al terruño que sólo un lugareño puede tener. Sin embargo, la visión de la Amazonía que en "Sangama" se transmite es contradictoria. Es decir, esta visión de la población ribereña se origina en un amor al terruño pero lo considera una fuente inagotable de recursos naturales que a la larga causará su destrucción. En otras palabras, parafraseando a William Howarth, cuando en "Sangama" se imagina la Amazonía ésta no tiene límites naturales. Las bien establecidas distinciones entre lugar y ser humano, el yo y el otro sostienen las ilusiones conocidas como amor o reverencia a la naturaleza. Pero la naturaleza no necesita el amor de los humanos, por el contrario los humanos necesitan con seguridad una naturaleza viva y saludable (509).

La marcada contradicción de está visión ribereña de la Amazonía se debe a varias razones. En principio el sujeto de conocimiento sería un sujeto post-colonial más complicado que el sujeto europeo en varios sentidos. Por un lado, el sujeto post-colonial poseería una particular percepción del espacio modelada por una concepción que ha hecho la separación entre sujeto de conocimiento y el objeto de conocimiento. Por otro lado, tal sujeto habría desarrollado una visión propia en correspondencia a una conciencia situacional que parte de la experiencia en el mismo lugar. Se trataría en otras palabras de una conciencia indígena del lugar. Esta conciencia situacional le da un privilegio epistémico que hace legítima la realización de la topografía y al mismo tiempo hace que sea reconocido como portavoz autorizado por sus lectores. ${ }^{11}$

11 Alberto Moreiras desarrolla más ampliamente estos conceptos (1996: 875-876). 
Las contradicciones de este sujeto de conocimiento se pueden rastrear en el pasado de la población ribereña. La mayoría de los ribereños son descendientes tanto de inmigrantes extranjeros como de los colonizadores nacionales que tuvieron que migrar por catástrofe ecológica y usurpación de sus tierras por los grupos de poder en sus lugares de origen. Estos inmigrantes bien sean estacionales o permanentes han tratado de imponer su sedentarismo, la práctica de la agricultura intensiva y el monocultivo. Estas dos prácticas, que ya provocaron la deterioro del medio ambiente serrano, tienen consecuencias catastróficas para el medio ambiente selvático que es destruido en corto tiempo. Asimismo, el deterioro del medio ambiente se constituye en un peligro para los mismos inmigrantes cuando son víctimas de lluvias que provocan inundaciones fluviales en la Selva Baja y avalanchas en la Selva Alta que destruyen rutinariamente pueblos enteros con varias pérdidas de vidas. Si bien las lluvias e inundaciones son imposibles de evitar, las avalanchas de barro son previsibles ya que ocurren como consecuencia de la deforestación de la Selva Alta.

Hay que agregar que la migración a la Amazonía ha sido promovida por los gobiernos de turno para resolver las contradicciones económicas y sociales del sistema capitalista periférico o cuando los recursos naturales de la selva adquieren valor de cambio en determinadas coyunturas económicas mundiales. En cualquier caso, la Amazonía ha sido concebida por el Estado peruano o los grupos en el poder como una fuente de soluciones para varios problemas ajenos a su población autóctona. Hasta donde se pueda rastrear esto ha ocurrido desde tiempos coloniales. Recuérdese, por ejemplo, que la leyenda de "El Dorado" fue utilizada por la administración colonial para deshacerse de una numerosa soldadesca que habiéndose terminado la conquista, sus habilidades militares se constituían en obstáculos para el avance de la empresa colonizadora. Este fenómeno se afianza en la república por lo que no extraña las políticas de colonización de la selva promovidas por el gobierno peruano con colonos europeos en el siglo XIX y luego la construcción de la marginal de la selva en el siglo XX. ${ }^{12}$

12. Aunque Santos Granero y Barclay se refieren a la historia de la selva central, las políticas de
colonización de la selva que enumeran afectaron también a la selva del Bajo Ucayali (1998). 
De otra parte la mayor parte la población ribereña ha recibido educación formal, con las limitaciones del caso, en un sistema de educación occidentalizado que les ha inculcado concepciones destructoras del espacio amazónico. Sin embargo, después de haber fracasado en sus esfuerzos de explotar el espacio amazónico han podido conocer la especificidad de este medio ambiente y asimismo han aprendido el conocimiento local de la población nativa. De este modo, se tiene un sujeto de conocimiento contradictorio, a caballo entre las dos concepciones conflictivas del espacio, aunque con una predominancia de concepciones occidentalizadas. Tales concepciones, en efecto, son reforzadas con el uso de medios de comunicación masivos que transmiten y legitiman el conocimiento dominante sobre la Amazonía y ponen en duda el conocimiento producto de la experiencia local.

Fuera de ello, en "Sangama" aparece otra contradicción que es propia del regionalismo amazónico. Aunque lo más probable sea que Abel Barcas tenga ascendencia serrana, él rechaza tanto la migración de compatriotas andinos como el proyecto de modernidad que puedan proponer. En las alusiones al origen de los migrantes que constituyen la población ribereña del Bajo Ucayali, se señala que provienen del departamento de San Martín. Por un lado, la historia confirma que la mayor parte de la población ribereña del Bajo Ucayali y el río Amazonas son los descendientes de inmigrantes de los departamentos de San Martín y Amazonas que llegaron a la selva por el "boom" del caucho entre 1870-1918 (Chibnik y de Jong 1992: 188). Aunque en el presente son monolingües hispanoblantes, en el departamento de San Martín y el Huallaga continúa viviendo el grupo étnico quechua lamista (Puga Capelli 1989:79-83). Sin embargo la muerte de Sangama, quien según sus propias palabras, está atado al pasado incaico (serrano) y sólo utiliza a la selva como base temporal para lanzar un proyecto de restauración del Imperio de los Incas, indicaría una cancelación de un proyecto que privilegia los intereses y la cultura serrana indígena.

En "Sangama" el proyecto de modernización es marcadamente regionalista. Es decir se propone un proyecto económico y político para la selva y hecho desde la selva. Este proyecto es propuesto tomando en cuenta 
los parámetros que impone un estado nación moderno. De allí que en "Sangama" se critique a la modernización emprendida por los agentes del estado nación y, al mismo tiempo, se insista en los mismos dispositivos modernizadores para poblar el territorio de la nación y para la formación de ciudadanos. En otras palabras, la principal crítica que se le hace al estado nación es que lleva a cabo una modernización que atrasa "porque al ser contradicha por las creencias y las prácticas tradicionales, los programas que la impulsan deben negociar su realización" (García Canclini 1995:9). Pero, en la novela se sigue concibiendo a la educación como el principal mecanismo de formación de ciudadanos selváticos y con el uso de una alegoría amorosa heterosexual se propone una modernización capitalista elaborada en la periferia.

Visto de esta manera, este proyecto sería el de una élite regional que no propone nuevas formas de organización económica, política y social o modalidades de explotación de los recursos naturales. En pocas palabras, lo único claro es que en "Sangama" se proponen nuevos agentes que llevarán a cabo una modernización capitalista de tipo extractiva. Es por ello, que el personaje Sangama resulta útil como el buen maestro que enseña a Abel Barcas muchos valores y conocimientos pero no puede ser el líder por su carácter foráneo. El proyecto de Sangama resulta ajeno a la selva porque si bien se va a iniciar en este espacio restablecerá el poder serrano.

Es oportuno señalar que la propuesta de modernización de "Sangama" se sostiene en cuatro elementos claves estrechamente interrelacionados. A saber: el conocimiento, espacio físico, la economía de tipo extractiva y el amor heterosexual. En la novela misma se encuentra el siguiente pasaje que resume con precisión la propuesta:

"...En mis deseos de encontrar medios de vida independiente y segura que me permitieran el sostenimiento de un hogar cómodo y digno de Chuya, pensé hacerme shiringuero; pero tropezaba con la imposibilidad inmediata de conseguir peones y recursos para las primeras operaciones ... También habia llegado a pensar en la posible protección del nuevo dueno, ya que mis servicios le aportarian la ventaja de mi conocimiento del lugar y de sus gentes..." (149-150)

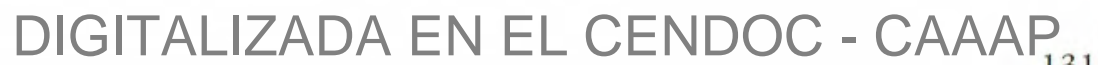


Chuya es la esposa perfecta. Abel Barcas la escoge porque cumple el requisito de haber nacido en la selva, ha recibido educación formal en la ciudad y genéticamente transmitirá la sabiduría de su padre Sangama, a sus hijos. Del mismo modo se insiste en la economía extractiva como mecanismo de acumulación de riqueza y el conocimiento local es el instrumento que sirve para optimizar la explotación del caucho. En este plan de vida el objetivo mayor es acumular riqueza para dejarla como herencia a sus hijos $y$, considerando las trayectorias de las reivindicaciones regionalistas, convertirse en poder político.

Por lo anteriormente señalado, hay que reiterar que en "Sangama" no se denuncia la catástrofe ecológica provocada por la explotación del caucho. Recuérdese que Abel Barcas retorna a la selva para seguir la explotación de esta materia prima. Tampoco se denuncia, salvo breves referencias, el holocausto indígena provocado por esta actividad extractiva que promovió las "correrías" para esclavizar mano de obra indígena y que atraía gente inescrupulosa. ${ }^{13}$ Más bien, la denuncia se focaliza en las vicisitudes que provocó el "boom" del caucho en la población ribereña. En efecto, en la novela se apunta que las arbitrariedades de los barones del caucho diezmaron a la población no indígena de las riberas de los/ríos amazónicos.

El tratamiento del tema de la explotación del caucho lleva a que la topografía de la novela adquiera un sentido más amplio. Es decir la novela es también una descripción de los efectos de la modernización capitalista en la Amazonía peruana que responde a intereses diferentes y contrapuestos a los de la población ribereña. En este sentido, por un lado, se alude a cómo la economía regional se inserta en la economía mundial con la extracción del caucho para la exportación. Por otro lado, se describe como el estado peruano ejerce una jurisdicción legal, viciada desde un principio, en una parte de su territorio cuando adquiere un nuevo valor económico. Es 
decir, el estado peruano toma interés en la Amazonía solamente cuando se constituye en una nueva fuente de riqueza tal como ocurrió con los "booms" del caucho, petróleo, oro y la explotación maderera que nunca ha dejado de cesar.

En "Sangama" no se profundiza el examen del tema de la economía extractiva regional la cual está inscrita en la economía mundial, sino que se critica las acciones de las autoridades del estado peruano que aprovechan el ejercicio de la ley en beneficio propio. Abel Barcas, que trabaja como secretario en la gobernación, relata cómo el gobernador Portunduaga, se enriquece inescrupulosamente con el comercio del caucho. En efecto, el gobernador que en un principio es bienvenido por el pueblo que piensa que va a controlar a los caciques locales, se constituye en un antihéroe al reunir en su persona todos los defectos que impiden una modernización de la selva. Como antihéroe su vida privada no es un modelo a seguir pero su vida pública como funcionario del estado sigue siendo un objetivo que se debe lograr. Es decir, el comportamiento de Portunduaga obstaculiza las posibilidades de modernización. Por un lado no puede modernizar la economía ya que no ahorra tampoco invierte sino malgasta su dinero en mujeres y juego. Por otro lado, no puede modernizar las instituciones sociales regionales porque es ignorante y no hace una aplicación justa de las leyes del estado. Portunduaga nombra la constitución y no las leyes para justificar legalmente la usurpación de tierras caucheras mediante el asesinato, el juego amañado de dados y de naipes o artimañas legales que resultan en la constitución de un poder económico (30). También, Portunduaga se apropia criminalmente de cargamentos de caucho listos para ser comercializados interviniendo en nombre de la ley y el orden del estado peruano. La apropiación es realizada con un plan que consiste en asesinar personas cuyos cadáveres son puestos por los cómplices del gobernador en las embarcaciones repletas de caucho para encarcelar a sus propietarios mientras se investigan los supuestos asesinatos. Por supuesto, el gobernador confisca el cargamento de caucho en nombre de la ley y negocia la escapatoria de la cárcel previo pago en tierras o caucho. Pero, conocedor del lugar al que se dirigen asesina a los acusados utilizando la ley de fuga (34-37). 
En la novela la modernización anómala de la sociedad amazónica termina con el uso de la justicia poética. El reino del terror y el imperio económico de Portunduaga desaparecen cuando Abel Barcas organiza un complot para destituirlo utilizando la ley del Estado. El complot funciona más allá de lo planeado. Portunduaga es asesinado por uno de sus propios secuaces que pierde el miedo a su autoridad cuando se entera de que su patrón ha sido sustituido (99-102). En otras palabras, ficcionalmente se cancela el proyecto de la "modernización que atrasa" con el propósito de recuperar la potencialidad de una verdadera modernización capitalista. Para ello, Abel Barcas utiliza una inteligencia maquiavélica que miente (medio) para lograr la destitución del gobernador (fin) y se justifica la mentira porque ha sido hecha en beneficio de la comunidad.

La auténtica modernización capitalista que va a desarrollar la selva se esboza en "Sangama". En este sentido se señala que

"..Noticias fidedignas procedentes de Iquitos, hacian esperar la pronta llegada de comisionados de la Justicia y de un capitalista que, aseguraban, habia adquirido la propiedad de los shiringales del gobernador y se proponía emprender en grande la explotación.." (149).

En efecto, llega el señor Ramón Rojas de Europa para tomar posesión de sus tierras recién compradas y busca a Abel Barcas como administrador (151). Abel Barcas aprecia sus "finas maneras" y firma un contrato que lo convierte en administrador de las propiedades ya compradas y dueño del cincuenta por ciento de las tierras caucheras que serán descubiertas (152). Precisamente la expedición hacia el Huallaga que se emprende para descubrir más tierras es la que lleva a la topografía de la selva virgen y al desenlace de la novela. Esta topografía describe el espacio, la flora y la fauna. También describe las creencias de los pobladores amazónicos como el "chullachaqui" (185), el "manchari" (255) y el "supay" (192). También en esta expedición Sangama demuestra su profundo conocimiento de la selva que lo lleva al desarrollo de extraordinarias habilidades de sobrevivencia. 
En "Sangama", aparte de narrar el fracaso de la modernización política como consecuencia de la corrupción de los funcionarios públicos, se remarca que la realidad misma obstaculiza el establecimiento de un estado nación moderno. Abel Barcas reflexiona sobre el hecho de que uno de los obstáculos es que el espacio selvático del Bajo Ucayali no permitía el establecimiento de hitos en las fronteras y por tanto límites precisos con los países limítrofes. Del mismo modo, las crecidas y cambios constantes del curso de los ríos no permiten en esta parte de la selva el establecimiento de asentamientos humanos permanentes. ${ }^{14}$ La población amazónica ribereña está obligada a tener una cuasi condición nomádica, desterritorializada por razones naturales, que los obliga a desconocer el lugar exacto de su nacimiento y de su nacionalidad. Por el constante cambio del espacio y la desaparición de archivos municipales por las inundaciones, tal como pasó en la vida misma de Hernández, muchos no saben la fecha exacta de su nacimiento y dudan si tienen la nacionalidad peruana. ${ }^{15}$ Sin embargo, la población ribereña insiste en la construcción de pueblos en contraste de los grupos étnicos que habitan esta región. Aunque los grupos étnicos repiten patrones de asentamiento dominantes debido a que están siendo rápidamente integrados en la economía capitalista con el consecuente olvido y cambio de sus saberes autóctonos en el presente, por muchos siglos fueron nómades ya que conocían la fragilidad e inestabilidad del espacio amazónico. Así no practicaban agricultura intensiva y monocultivo. En consecuencia

El siguiente pasaje alude a este fenómeno: “- ¡Pero si lo recuerdo muy bien! ¡Aqui, en este mismo sitio, habia, cuando pasé hace cuatro años, una poblacioncita con gentes y ganado. En el puerto, varios árboles del pan brindaban su sombra...! - Pero, señor, el sitio que ese pueblo ocupó ha quedado, cuando menos, a diez kilómetros al interior. El pueblo tuvo necesariamente que desaparecer. El rio ha formado delante una playa extensa que ha sido cubierta por nutrida vegetación... Asi se han ido formando otras playas sucesivas, hasta que ha quedado lo que usted ve: selva, nada más que selva"(50).

15 "El viajero que inició la conversación, se aproximó cauteloso y me dijo: - Oiga Ud. Yo no sé dónde he nacido. - ¡Cómo! -repuse asombrado- ¿Es posible lo que Ud. Afirma? - Es que tengo mis dudas. Verá Ud. Yo nací, hace veinticinco años, en la margen oriental de este río, en un punto llamado Sintico. Desde entonces, las aguas no cesan de 'comer' por el lado opuesto, de moque que el lugar a me refiero parece que ha ido quedando atrás kilómetros y kilómetros. ¡A lo mejor, yo nací en un punto geográfico que ahora queda en el Brasil!”(6). 
no provocaron catástrofe ecológica y tampoco fueron víctimas de las catástrofes naturales generadas por la destrucción de su medio ambiente.

De otra parte, en "Sangama" también se propone que el fracaso de la implementación de la modernidad política se debe al centralismo y al desequilibrio entre obligaciones y deberes que exige el estado a sus ciudadanos. Por este motivo, las instituciones y autoridades del estado peruano no son aceptadas por la población ribereña. La población ribereña del pueblo de Santa Inés, no desea el establecimiento de las autoridades estatales puesto que éstas sirven para exigir el cumplimiento de mayores deberes para la nación que derechos de ciudadanos (19-20). En la novela se menciona revueltas locales fácilmente manipuladas que canalizaron reivindicaciones regionales a un estado centralista y el reestablecimiento temporal de los intereses locales con la destitución o asesinato de autoridades corruptas. Digo temporal, porque el estado siempre vuelve a reestablecer el orden con la violencia que la caracteriza y los pobladores son conscientes de ello. Sin embargo, estas revueltas o asesinatos selectivos ejecutados por la población amazónica no tienen un carácter secesionista. Lø que desea la población ribereña son autoridades más honestas y justas. Para demostrar este punto de vista, en la novela se relata el caso de individuos que defienden el territorio peruano frente a los afanes expansionistas del Brasil (406-407). Del mismo modo critica la política de entrega de territorios con la firma de un tratado internacional al Brasil (408-409). ${ }^{16}$

En "Sangama" el primer paso que se debe dar para hacer realidad esta propuesta de modernización regional es la formación de sujetos ciudadanos con un sistema de educación formal. Así otra vez la educación es considerada como factor importante de construcción social tal como ocurre en la formación del estado-nación moderno. La asunción implícita de esta

\footnotetext{
16 Hernández tenía una conciencia regionalista bastante arraigada. El participó en la rebelión de Iquitos de Guillermo Cervantes (1921) contra el presidente Augusto B. Leguía. Luego que la rebelión fue reprimida por el ejército Hernández fue apresado y llevado a la cárcel de Lima. (Alegría 1986:47).
} 
confianza en la educación es la asociación que existe entre conocimiento y virtud. Al igual que el pensamiento ilustrado, en "Sangama" se sigue creyendo que el conocimiento racional adquirido a través de la educación lleva a una conducta virtuosa. De este manera, considera que se debe "civilizar" o educar a la población ribereña ignorante, supersticiosa y fácilmente manipulable por cualquier tipo de líder. Para graficar el carácter veleidoso de la población utiliza las dicotomías superstición / conocimiento racional, brujería / medicina y narra la conspiración que trama el brujo Dawa contra Sangama. Dawa se convierte en enemigo a muerte de Sangama debido a que no le dio la mano de su hija Chuya (14-16). Del mismo modo se relata la revuelta del pueblo de Santa Inés, otra vez incitada por Dawa, que quiere "inmolar" a la amante del gobernador cuando se dan cuenta que tuvo relaciones sexuales con el cura visitante. El pueblo de Santa Inés reacciona de este modo porque tienen la superstición de que primero la mujer que se acuesta con un cura se convierte en mula y luego traerá la calamidad al pueblo (49-56).

De otra parte, demanda mayor autonomía regional. Considera que el poder político y las empresas económicas en la selva deben estar a cargo de lugareños educados y por tanto honestos y justos. Como ejemplo de esta nueva población ribereña se pone a si mismo y a Chuya, la hija de Sangama, que fueron "civilizados" en la ciudad de Lima pero retornaron a sus lugares de origen para establecer el progreso. ${ }^{17}$ Del mismo modo, en "Sangama" se manifiesta otra vez una fe en la ciencia cuando Sangama señala con admiración la presencia de científicos europeos que residen en la selva y desentrañan los secretos de la naturaleza (136-137).

La creencia en el proyecto ilustrado no es ciego, tampoco el uso de sus categorías es irreflexivo. En "Sangama" por un lado se hace una ligera

17 “... Chuya, desbordante de contento, juventud y lozanía dio rienda suelta a sus recuerdos de Lima. Nos habló del conventual colegio, de sus estudios dirigidos por suaves monjitas, de fiestas religiosas, de sus condiscípulas. Hizo tanto derroche de precisión, propiedad y colorido en las descripciones, que admirado, no pude evitar una exclamación: - Es Ud. una persona muy culta ,señorita. - No; una selvática que fué a la civilización y procuró sacar algo de ella." (107-108).

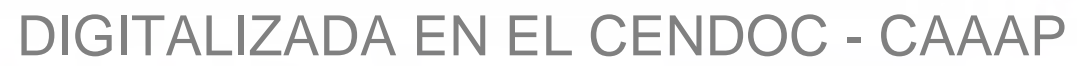


crítica del carácter universal de la dicotomía civilizado / salvaje mostrando que esta categoría fue elaborada desde la perspectiva del que se considera civilizado. Del mismo modo critica la categorización de la selva como territorio del salvaje. Finalmente, señala los fracasos de las empresas de los "civilizados" al querer aplicar conocimientos ajenos antes de estudiar y observar la selva (130-131). Por último, se considera que:

“...en la selva todos se transforman. Nuestra naturaleza ingénita ... surge súbitamente y se nos impone apenas tenemos contacto con la selva. Aqui, el civilizado se despoja de la máscara con que engaña al mundo, no teme la represión ni la censura del medio..."(59).

Abel Barcas aprecia la ciencia europea pero considera que debe ser complementada con otros conocimientos. Así tiene respeto por el conocimiento adquirido de personas no académicas que proceden con el método científico. Por esta razón, admira a Sangama que se convierte en un especialista de una eficiente medicina alternativa luego de haber observado, experimentado y llegado a conclusiones. Muchas de las aventuras narradas por Abel Barcas grafican el conocimiento profundo que también tiene Sangama de la flora, fauna y suelo cuando guía a Abel Barcas en su desplazamiento por la selva virgen.

Para legitimar el proyecto ribereño también se reflexiona sobre el pasado y la tradición. En "Sangama" se señala que la Selva no tiene historia debido a que no se ha desarrollado una civilización superior que haya podido influir a otras culturas (161). ${ }^{18}$ Según Barcas, la selva está básicamente poblada por salvajes que por un lado practican la reducción de cabezas, desangramientos de jóvenes varones para "templar el carácter" y la cliterectomía. Por otro lado, tienen prácticas exóticas como la deformación

$18 \quad$ Arturo Hernández en su novela y en declaraciones públicas ha reiterado que la selva no tiene historia. Por ejemplo, declara: “... la selva no tiene historia y en un medio elemental como en el que se desarrolla “Sangama” el personaje central de la obra tenía que fracasar... "(Alegría 1986:48). 
de cabezas, afilamiento de dientes, partos en el agua (142-148). Por cierto, se narran estas prácticas culturales con cierta dosis de relativismo cultural pero en definitiva se considera que los grupos étnicos amazónicos son salvajes que no han alcanzado un alto grado de civilización y por tanto carecen de historia. Pero esta idea va a contrapelo de la investigación arqueológica que ha acumulado suficientes evidencias para apuntar lo contrario. ${ }^{19}$ Es decir que el origen de las civilizaciones andinas es amazónico. De otra parte, en "Sangama", se dice que:

“...Esta zona geográfica [la del Bajo Ucayali] ha sido poblada en su mayor parte por el arrojo de las gentes del departamento de San Martín, sede de poblaciones antiquísimas en el Oriente del Perú. Intrépidos exploradores encontráronse, al recorrer la selva en busca de cauchales, con el imponente río que los antiguos descubridores denominaron Ucayali..."(3).

En este pasaje, se considera que la selva estaba casi vacía y es poblada cuando inmigrantes de la ceja de selva se internan en ella en busca de caucho. De esta manera, la selva tiene una historia reciente que empieza con el asentamiento de inmigrantes que practican una economía de extracción. En pocas palabras, con los inmigrantes de San Martín empieza la historia de la Amazonía y se confirma que estos inmigrantes trajeron otra concepción sobre el medio ambiente y consideran que la Amazonía es un espacio con ilimitados recursos que deben ser extraídos.

El señalamiento de la inmigración a la selva como origen de la población amazónica también es excluyente. Por un lado, se excluye de ella a los grupos étnicos amazónicos. Por otro lado, no todos los inmigrantes tienen el derecho de dirigir el proyecto regionalista. Los inmigrantes autorizados

19 Los cronistas españoles describen una selva bastante poblada en el siglo XVI. Sólo para mencionar, la arqueóloga Roosevelt señala que hay restos arqueológicos que demuestran el desarrollo de civilizaciones complejas en la Amazonía mucho antes que en la Sierra. 
son los de la ceja de selva, los europeos pero no los serranos. Está exclusión se propone de una manera indirecta cuando se reformula el mito del Inkarri. Sangama cree que es el descendiente de un grupo de Incas que se internaron a la Selva alta para escapar de las huestes del virrey Toledo (1572) y mantener la posibilidad de un retorno incaico (228-233). Sangama como descendiente de este grupo de Incas tiene que llevar a cabo una rebelión para restaurar el Tahuantisuyo por su inmanente carácter moral y religioso (136). Para ello aprende todos los secretos de la Amazonía y busca un tesoro que sus ancestros dejaron para financiar la rebelión (234). Sin embargo, cuando se da cuenta de que no puede llevar a cabo su misión se suicida. Abel Barcas, no da su opinión sobre la misión fallida de Sangama. El mismo Sangama antes de suicidarse declara:

“...jYo amé la selva, lo repito! Largos años me acogió en su seno. Mi juventud y todo el resto de mi vida transcurrieron en una perenne curiosidad por penetrar sus secretos, hondos e indescifrables. Y fui feliz, porque viví amoldándome a sus leyes. Así hubiera podido terminar mis dias en ella, sin más preocupaciones que estudiarla constantemente y aportar a la ciencia el acervo de insospechados y valiosos conocimientos. Pero...tenía el alma saturada de Pasado. ¡Mi sangre, la médula de mis huesos, todo mi ser estaba nutrido de ese motivo que alentó a mis ascendientes y fue la única razón por la que vivieron y perecieron! ; Un hombre asi debió haber sido sepultado hace siglos! ;Muy tardio fue mi despertar! ;Ya estoy vencido, incapacitado para emprender una nueva vida!..." (473).

La novela termina cuando Abel Barcas, luego de presenciar el suicidio de Sangama en el pongo de Aguirre, espacio liminal entre sierra y selva, retorna a la selva acompañado de Chuya, la hija de Sangama, diciendo:

"...comenzamos a descender lentamente, del elevado reino de las nubes, hacia el fecundo y maravilloso regazo de la Madre Tierra: la Selva..." (475). 
Claro está que este final es alegórico en el que la relación amorosa de Abel Barcas y Chuya representa la conjunción de dos sectores de población selvática que llevarán a cabo la modernización de la selva. ${ }^{20}$ Abel Barcas el joven del pueblo ribereño y Chuya la joven del fundo interior harán una vida promisoria explotando el caucho de la selva. Abel Barcas no cometerá los errores de su padre y el gobernador en la explotación de caucho. El ahorro y la reinversión serán sus objetivos económicos para alcanzar la formación de un capital. Su proyecto de modernización es la constitución de una elite culta regional que proponga el desarrollo de la Amazonía a través de la aplicación de un conocimiento profundo de ella, resultado de la ciencia europea que aprendió a través de una educación formal y el conocimiento autóctono que aprendió de Sangama a través de la experiencia y el diálogo. Esta modernización será asegurada por Chuya que por un lado tiene una educación urbana occidentalizada y por otro lado es la heredera de la sabiduría de su padre que, en su condición de madre, será transmitida a los hijos que, por supuesto en esta concepción tradicional de la mujer, tendrá con Abel Barcas.

\section{BIBLIOGRAFIA}

\section{ALEGRÍA, C. et. al.}

1986 Primer Encuentro de Narradores Peruanos. 2da. ed. Latinoamericana Editores. Lima.

\section{ALONSO, C. J.}

1990 The Spanish American Regional Novel: Modernity and Autochthony. Cambridge University Press. Cambridge; New York.

20 Son útiles las propuestas de Doris Sommer de que las relaciones amorosas en la novela latinoamericana son alegorías de construcción de la naciones en el que cada personaje representa a un grupo o sector social en alianza o conflicto. 
BRACK EGG, A.

1992 "La Amazonía. Problemas y posibilidades" Amazonía Peruana XI: 21: 9-22.

CHIBNIK, M. y W. DE JONG

1992 "Organización de la mano de obra agrícola en las comunidades ribereñas de la Selva Peruana”. Amazonía Peruana XI: 21:181216.

DELGADO, W. y A. HERNÁNDEZ

1986 Diccionario histórico y biográfico del Perú. Siglo XV-XX. . Editorial Milla Batres. Tomo IV. Lima

DUCAN J. y D. LEY (ed.).

1993 Place / Culture / Representation. Routledge. Londres y Nueva York.

GARCÍA CANCLINI, N.

1995 "Una modernización que atrasa: Las contradicciones socioculturales en América Latina”. Journal of Latin American Anthropology 1: 1:2-19.

\section{HERNÁNDEZ, A.}

1942 Sangama, novela de la selva amazónica. Imp. Torres Aguirre. Lima.

HOWARD, W.

1999 "Imagined Territory: The Writing of Wetlands". New Literary Review 30: 509-539.

MARCONE, J.

1998 "De retorno a lo natural: La serpiente de oro, la "novela de la selva" y la crítica ecológica" Hispania 81: 2. 
MOREIRAS, A.

1996 "Elementos de articulación teórica para el subalternismo latinoamericano. Cándido y Borges”. Revista Iberoamericana 176177: 875-891.

PUGA, A.

1989 “Es posible definir las fronteras étnicas? El caso de los Quechua Lamistas. "Amazonía Peruana IX: 17: 79-96.

RODRÍGUEZ, I.

1997 "Naturaleza/Nación: Lo salvaje/civil escribiendo Amazonia". Revista de Crítica Literaria Latinoamericana 23: 45 (1997).

ROOSEVELT, A.

1989 "Lost Civilizations of the Lower Amazon"Natural History 56.

SÁNCHEZ, Luis A.

1942 Literatura Peruana. Tomo II.

SANTOS-GRANERO, F.

1998 "Writing History in to the Landscape: space, myth and ritual". American Ethnologist 25: 2.

SOMMER, D.

1991 Foundational fictions : the national romances of Latin America. University of California Press. Berkeley.

TOURNON, J.

1988 "Las inundaciones y los patrones de ocupación de las orillas del Ucayali por los Shipibo-Conibo”. Amazonía Peruana VIII: 16: 43-62.

VARGAS LLOSA, $M$.

1969 "Novela primitiva y novela de creación". Revista de la Universidad de México Vol.XXIII: 10. 
Amazonía Peruana

ZEVALLOS AGUILAR, J.

1989 "La experiencia de Avanzada. Misiones, medios masivos e identidad amazónica". Amazonía Peruana IX: 17: 139-152. 